\title{
CORROSION OF TIN, (TiAl)N and CrN HARD COATINGS PRODUCED BY MAGNETRON SPUTTERING
}

\author{
L. Cunha, M. Andritschky, L. Rebouta, R. Silva
}

Departamento de Física, Universidade do Minho, Largo do Paco, 4719 Braga Codex, Portugal; Fax: xx 35153678981

‡. Instituto Superior de Engenharia do Porto, Rua S. Tomé, 4200 Porto, Portugal.

\begin{abstract}
Metallic components like moulds, dies and machinery can be subjected to intensive degradation during plastic transformation processes, namely when working with fibre filler materials and plastics which release $\mathrm{F}, \mathrm{S}$ or $\mathrm{Cl}$ during transformation. The degradation is attributed to the combined erosive and abrasive wear by the filler material and corrosive attack of agents. This degradation reduces the lifetime of the components considerably and has a direct impact on process productivity and surface finish of the final products.

Nitride based hard coatings like TiN, (TiAl)N, BN, etc. have proved their capability to increase tool lifetime when exposed to abrasive and corrosive environments found in plastic transformation processes (halogenated polymers, acrylics, polyesters, fibre reinforced plastics, etc.).

Within the frame of this work we produced TiN, (TiAl)N, CrN hard coatings, with and without a metallic interlayer, by DC and RF reactive magnetron sputtering, with a thickness of about $2 \mu \mathrm{m}$. The aqueous corrosion behaviour of the coatings was studied in saline and acidic environments by potentiodynamic and open circuit potential (OCP) measurements. The oxidation resistance during annealing in air was also studied.

In saline ( $\mathrm{NaCl}$ 9\%) and acid ( $\mathrm{HCl} 3.4 \%)$ environments we found that a metallic interlayer of $\mathrm{Ti}$ or $\mathrm{Cr}$ in the case of TiN / (TiAl)N coated samples and CrN coated samples, respectively, generally improve the corrosion resistance. Best results for all tested nitride coated samples were obtained for the $\mathrm{Ti}_{.27} \mathrm{Al}_{.73} \mathrm{~N}$ coating. The OCP vs. Saturated Calomel Electrode (SCE) (60 min) measurements indicated that most samples were nobler than the un-coated substrate. The mentioned potentials depend on the deposition conditions and the film microstructure. Most of the coatings lose some of
\end{abstract}


their protective capabilities after an high temperature annealing. In contrast to the Ti based hard coatings, the corrosion resistance of $\mathrm{CrN}$ is improved by a $800^{\circ} \mathrm{C}$ annealing treatment in air.

\section{Introduction}

Filled and fibre reinforced plastics are increasingly applied during plastic manufacturing. These materials cause by the combined abrasive and corrosive attack of hard fibres and F, S, $\mathrm{Cl}$ from plastic decomposition a substantial reduction of the lifetime of machinery, dies and moulds [1].

Hard coatings of metal nitrides such as $\mathrm{TiN},(\mathrm{TiAl}) \mathrm{N}, \mathrm{CrN}$ and $\mathrm{BN}$ have proven their capability to increase tool lifetime not only during abrasive action of hard materials but also in many chemically aggressive environments [2]. These hard coatings are generally deposited by PVD or by CVD deposition techniques. Due to the required high substrate temperatures, the CVD deposition technique is applied to a lesser extent than the PVD techniques to protect the machinery in the plastic transforming processes. The microstructure of PVD coatings is characterised by a columnar microstructure and corrosive problems during application are generally attributed to the voids between these columns, to pinholes and to eventually existing cracks. Therefore local corrosion may cause an accelerated degradation of the metallic substrate. Furthermore, nitride coatings, operating at higher temperatures are prone to be oxidised, forming $\mathrm{TiO}_{2}, \mathrm{Al}_{2} \mathrm{O}_{3}, \mathrm{Cr}_{2} \mathrm{O}_{3}$, mixed oxides, etc. These oxide layers generally control the kinetics of the oxidation at higher temperatures and may also close the above mentioned coating defects. Nevertheless, the chemical properties of the oxide layers are different from those of the nitrides.

Within the frame of this work we studied the corrosion of substrates protected by several multilayered hard coatings $(\mathrm{TiN},(\mathrm{TiAl}) \mathrm{N}, \mathrm{CrN})$ in two different aqueous solutions $(\mathrm{NaCl}$ and $\mathrm{HCl})$, as well as the oxidation resistance of the coatings during annealing at $700^{\circ} \mathrm{C}$ in air. Furthermore, the corrosion protection of an about $100 \mathrm{~nm}$ thick oxide layer, grown by thermal oxidation on the coatings, was studied. The aim of the study is a first selection of coating materials taking into account not only the corrosion protection in an aqueous environment but also oxidation at higher temperatures. The study of the combined effect of high temperature, oxidation and corrosive agents is not included in this work. Since the colour of the coatings is a property very sensible to all kind of chemical variation of the surface, including corrosion, we included some colour measurements in the 
study. We hope to initiate some systematic studies on this topic eventually giving origin to some non-destructive coating evaluation technique.

\section{Experimental Details}

The coatings were deposited onto mechanically polished stainless steel (AISI 316) by reactive magnetron sputtering in an Alcatel SCM 650 system. The average surface roughness before and after the coating deposition was about $0.7 \mu \mathrm{m}$. Before coating deposition, the substrates were ultrasonically cleaned and, in situ, r.f. sputter etched in a pure Argon atmosphere to remove the native oxide scale. Coatings were deposited from pure metal targets in an Argon and Nitrogen atmosphere (about $5-10 \% \mathrm{~N}_{2}$ during the TiN and (TiAl)N deposition and about $40 \% \mathrm{~N}_{2}$ during the $\mathrm{CrN}$ deposition) at a total pressure of $0.45 \mathrm{~Pa}$. The Ti and $\mathrm{Cr}$ targets were separately coupled to a r.f. source, while the Al target was DC biased. During coating deposition, substrates were heated to $300^{\circ} \mathrm{C}$, a DC bias of - $50 \mathrm{~V}$ was applied and they rotated above the targets at a distance of $60 \mathrm{~mm}$. During most runs a thin, pure metal layer $(0.7 \mu \mathrm{m} \mathrm{Ti}$ and $0.7 \mu \mathrm{m} \mathrm{Cr}$, respectively) was deposited onto the metallic substrate prior to the nitride deposition. In table 1 the composition and thickness of the coatings are indicated. After coating deposition, two oxidation experiments were done with most samples. The (TiAl)N and $\mathrm{CrN}$ samples were annealed in air at $850^{\circ} \mathrm{C}$ and $800^{\circ} \mathrm{C}$ resulting in an about $0.1 \mu \mathrm{m}$ thick pure $\mathrm{Al}_{2} \mathrm{O}_{3}$ and $\mathrm{Cr}_{2} \mathrm{O}_{3}$ layer, respectively [8]. In the case of the (TiAl)N coatings, they formed an additional $\mathrm{TiAlO}_{\mathrm{x}}$ intermediate layer [17]. (The TiN coatings were not annealed due to the very high oxidation rate of this nitride). These runs were solely done to produce the pure oxide layer on the sample surface prior to the corrosion experiments. It should be mentioned that this high temperature treatment is a relatively rough treatment which may cause additional defects due to thermal stresses.

A second set of samples was annealed at $700^{\circ} \mathrm{C}$ in air for $1 \mathrm{~h}$. These samples were analysed afterwards by Rutherford Backscattering Spectroscopy (RBS) measurements to determine the oxide layer thickness and, hence, the oxidation rate.

The electrochemical experiments were performed in a $9 \%$ solution of $\mathrm{NaCl}$ and in a $3.4 \%$ solution of $\mathrm{HCl}$ relative to a $\mathrm{Pt}$ - electrode and a $\mathrm{SCE}$ - electrode. Two types of experiments were done: (i) a potentiodynamic measurement from $-500 \mathrm{mV}$ to $+500 \mathrm{mV}$ with a scan speed of $15 \mathrm{mV} / \mathrm{min}$, in order to study the corrosion current on the basis of the Tafel analysis; (ii) an open 
circuit potential measurement (OCP) tomeasure eventually occurring passivation during an 60 min run in the test solution.

Rutherford Backscattering Spectrometry (RBS) and Energy dispersive X-ray analyses (EDX) were used to study the coating composition. RBS was used to determine the compositional depth profiles resulting from the oxidation experiments.

The total reflectance spectra of the samples were measured in a Shimadzu UV-3101 PC spectrophotometer. The colour of the sample surfaces was analysed on the basis of the $L^{*} a^{*} b^{*}$ colour system ( $L^{*}$ - lightness factor; $a^{*}, b^{*}$ - chromaticity). The colour difference of the samples before and after the corrosion test (in $\mathrm{HCl} 3.4 \%$ ) was calculated, using eq.1 [14-16]:

$\Delta E\left(L^{*} a^{*} b^{*}\right)=\left[\left(\Delta L^{*}\right)^{2}+\left(\Delta a^{*}\right)^{2}+\left(\Delta b^{*}\right)^{2}\right]^{1 / 2}$

eq. 1

With respect to the results discussed later it should be mentioned, that:

(i) a negative variation of $\mathrm{L}^{*}$ indicates, that the corroded area becomes darker, (ii) a negative variation of the chromaticity parameter $\mathrm{a}^{*}$ means that the colour of the sample becomes more blue and (iii) an increase in the $b^{*}$ coordinate is caused by a colour variation towards red. For example, white rust, as it is found in some corrosion experiments of metals, would cause an increase in $\mathrm{L}^{*}$.

\section{Results and Discussion}

The ability for corrosion protection of PVD coatings generally depends on their microstructure. In the table we present the experimental results for optimised coatings. Coatings with poor microstructure or high defect density due to insufficient substrate bias, insufficient temperature, poor polishing, etc. are not presented, although experiments were done. Furthermore, for all coatings, a pure metal interlayer ( $\mathrm{Ti}$ for the TiN and (TiAl)N coatings and $\mathrm{Cr}$ for the $\mathrm{CrN}$ coatings) improved the corrosion protection substantially and therefore, generally, samples with these interlayers are listed in table 1.

\subsection{Electrochemical measurements}


The hard coatings tested are able to reduce substantially the corrosion in a saline environment $(\mathrm{NaCl})$. Best results were obtained for both $(\mathrm{TiAl}) \mathrm{N}$ coatings. Nevertheless, after annealing the behaviour of the coatings is different. Then, all coatings tested in the same saline environment show relatively high corrosion rates. The (TiAl)N coating with the higher Ti content showed an increased corrosion rate compared to the metallic $\mathrm{Ti}$ layer. After annealing the $\mathrm{CrN}$ showed the lowest corrosion rates due to the presence of $\mathrm{Cr}_{2} \mathrm{O}_{3}$. These results are summarised in fig. 1 . Generally, the corrosion was relatively low and the overall corrosion (the integrated corrosion current during one sweep) was about $0.1 \mathrm{Cb} / \mathrm{cm}^{2}$ which corresponds to the removal of $\mathrm{Ti}^{++}$from an about $90 \mathrm{~nm}$ thick layer which apparently does not cause a visible colour variation. TiN and Ti show the best passivation behaviour (highest OCP) which is generally attributed to the formation of $\mathrm{TiO}_{2}$ [6]. $\mathrm{Cr}$ and even worse, $\mathrm{Al}$, which is enriched in the form of $\mathrm{Al}_{2} \mathrm{O}_{3}$ during the annealing procedure, reduce the passivation potential of the coatings.

In the acid environment $(\mathrm{HCl} 3.4 \%)$ corrosion currents are generally two orders of magnitude higher than the corrosion in the $\mathrm{NaCl}$ solution. Most corrosion tests show clearly visible colour changes, as indicated in the table and in fig.2. Compared to the bare substrate, metallic Ti layer improves the corrosion resistance by a factor of 3 and another factor of 2 might be gained by the application of the hard coating. After annealing the corrosion current increased, being again best for the oxidised CrN coating. The worst corrosion behaviour was found for the Ti-rich (TiAl)N coating which both, in the as deposited and in the annealed form showed higher corrosion rates than the metallic Ti layer on the stainless steel substrate.

It should be noted that the TiN (with Ti interlayer) showed the best pitting potential of all coatings, which again can be attributed to the formation of $\mathrm{TiO}_{2}$. The pitting potential of the $\mathrm{Ti}_{.27} \mathrm{Al}_{.73} \mathrm{~N}$ coatings in saline environment was also relatively high.

\subsection{Oxidation resistance behaviour}

The oxidation experiments were performed at high temperatures which are not relevant for plastic processing. Furthermore, at these temperatures some oxides and oxynitrides, which would 
not form at lower temperatures, have formed. Nevertheless, a preliminary trend can be indicated. The oxidation rate of the CrN sample is about 10 times higher than the one of the (TiAl)N samples. Within the (TiAl)N samples small differences can be found in the oxidation rate depending on composition. In any sample forms a 2 layered structure with a relatively thin $\mathrm{Al}_{2} \mathrm{O}_{3}$ toplayer and a $\mathrm{TiAlO}_{\mathrm{x}}$ layer between the $\mathrm{Al}_{2} \mathrm{O}_{3}$ and the $(\mathrm{TiAl}) \mathrm{N}$ coating. But it should be mentioned, that for very low and very high $\mathrm{Al}$ concentrations ( $\mathrm{Al}<20 \%$ or $\mathrm{Al}>75 \%$ ), the oxidation rate increases dramatically.

\section{Conclusions}

The results obtained by corrosion measurements of differently treated hard coatings can be summarised as follows:

(i) The corrosion resistance of hard coatings like $\mathrm{TiN},(\mathrm{TiAl}) \mathrm{N}, \mathrm{CrN}$ depends very much on their microstructure. Generally, fine grained coatings (improved by a substrate bias) show best corrosion protection.

(ii) The corrosion of $\mathrm{TiN}$, $(\mathrm{TiAl}) \mathrm{N}$ and $\mathrm{CrN}$ coatings in a saline $(\mathrm{NaCl})$ environment may be reduced up to two orders of magnitude. Best results were obtained with a bi-layered coating consisting in a 2 $\mu \mathrm{m}$ thick hard coating and a thin metallic $\mathrm{Ti}$ or $\mathrm{Cr}$ intermediate. In an acid environment $(\mathrm{HCl})$ corrosion protection was much less (up to a factor of 6) with respect to the unprotected stainless steel substrate.

(iii) Annealing of the coating at $850^{\circ} \mathrm{C}$, accompanied by the production of a $\mathrm{Al}_{2} \mathrm{O}_{3}$ surface layer, reduces the protective capability of a $(\mathrm{TiAl}) \mathrm{N}$ hard coating. A similar treatment (annealing for $1 \mathrm{~h}$ at $800^{\circ} \mathrm{C}$ with the production of a $\mathrm{Cr}_{2} \mathrm{O}_{3}$ layer) improves the protective capability of a $\mathrm{CrN}$ coatings in both aqueous solutions studied.

(iv) The heavy corrosion in the acid solution caused a significant variation of the surface colour. The absolute variation $\Delta \mathrm{E}$ depends, of course, on the coating composition.

\section{Acknowledgements}


The authors are grateful to Mr. Luís Rocha (Department for Mechanical Engineering, University of Minho) for useful discussions related to the corrosion experiments.

\section{References}

[1] G. Paller, B. Matthes, W. Herr and E. Broszeit, Materials Science and Engineering, A140 (1991) 647.

[2] A. Schröer, W. Ensinger and G. K. Wolf, Materials Science and Engineering, A140 (1991) 625.

[3] Y. Massiani, A. Medjahed, P. Gravier, J. P. Crousier, Thin Solid Films, 217 (1992) 31.

[4] J. Aromaa, H. Ronkainen, A. Mahiout and S.-P. Hannula, Surface and Coatings Technology, 49 (1991) 353.

[5] M. Fontana , Corrosion Engineering, McGraw-Hill, New York, 1987.

[6] L. P. Ward, Proceedings of Euroworkshop on Advances in Material Processing and Characterization Technologies, Dublin (1995) 79.

[7] A. A. Adjaottor, E. I. Meletis, S. Logothetidis, I Alexandrou, S. Kokkou, Surface and Coatings Technology, 76 (1995) 142.

[8] L. Rebouta, F. Vaz, M. Andritschky, M. F. Silva, Surface and Coatings Technology, 76-77 (1995) 70.

[9] Y. Massiani, A. Medjahed, J. P. Crousier, P. Gravier, I. Rebatel, Surface and Coatings Technology, 45 (1991) 115.

[10] U. K. Wiiala, M Penttiinen, S. Korhonen, J. Aromaa, H. Ronkainen, E. Ristolainen, Surface and Coatings Technology, 41 (1990) 191.

[11] M. Wittmeer, J. Noser, H. Melchior, Journal of Applied Physics, 52 (1981) 6659.

[12] F. Suni, D. Sigurd, K. T. Ho, M. A. Nicolet, Journal of Electrochemistry Society, 130 (1983) 121.

[13] A. Joshi, H. S. Hu, Surface and Coatings Technology, 76-77 (1995) 499.

[14] G. Wyszecki , W. S. Stiles, Color Science - Concepts and Methods, Quantitative Data and Formulas, John Wiley \& Sons, New York, 1967.

[15] D. B. Judd, G. Wyszecki, Color in Business, Science and Industry, John Wiley \& Sons, New York, 1975. 
[16] R. Mcdonald, Colour Physics for Industry, Society of Dyers and Colourists, Bradford, 1987.

[17] L. Rebouta, F. Vaz, M.Andritschky, to be published.

\section{Tables and Figures}

\begin{tabular}{|c|c|c|c|c|c|c|c|c|c|c|}
\hline Sample & $\begin{array}{l}\text { Coating } \\
\text { composition }\end{array}$ & $\begin{array}{l}\text { layer } \\
\text { thickness } \\
{[\mu \mathrm{m}]}\end{array}$ & $\begin{array}{c}L^{*} \\
\text { before/after\$ } \\
\mathrm{HCl}\end{array}$ & $\begin{array}{c}a^{*} \\
\text { before/after\$ } \\
\mathrm{HCl}\end{array}$ & $\begin{array}{c}b^{*} \\
\text { before/after } \$ \\
\mathrm{HCl}\end{array}$ & $\begin{array}{c}i_{\text {corr }} \\
{\left[\mu \mathrm{A} / \mathrm{cm}^{2}\right]} \\
\mathrm{NaCl}\end{array}$ & $\left.\begin{array}{c}i_{\text {corr }} \\
{\left[\mu \mathrm{A} / \mathrm{cm}^{2}\right]} \\
\mathrm{HCl}\end{array}\right]$ & $\begin{array}{l}O C P \\
{[\mathrm{mV}]} \\
\mathrm{NaCl}\end{array}$ & $\begin{array}{c}O C P \\
{[\mathrm{mV}]} \\
\mathrm{HCl}\end{array}$ & $\begin{array}{c}\mathrm{Kp} \\
{\left[\left(\mathrm{kgO}_{2} / \mathrm{m}^{2}\right)^{2} / \mathrm{s}\right]} \\
\text { at } 700^{\circ} \mathrm{C}\end{array}$ \\
\hline substrate & --- & 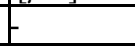 & \begin{tabular}{|l|}
$80.73 / 65.11$ \\
\end{tabular} & $0.017 / 1.812$ & $3.206 / 15.58$ & $2.9 \times 10^{-2}$ & \begin{tabular}{|l|}
4.1 \\
\end{tabular} & -125 & -362 & \\
\hline TN1 & $\mathrm{Ti}_{1} \mathrm{~N}_{1}$ & 2.3 & $76.11 / 75.15$ & $2.800 / 2.771$ & $30.79 / 30.22$ & $3.6 \times 10^{-2}$ & 0.33 & 220 & -260 & $3.5 \times 10^{-9}$ \\
\hline TTN1 & $\mathrm{Ti} / \mathrm{Ti}_{1} \mathrm{~N}_{1}$ & $0.7 / 2.5$ & $77.79 / 78.27$ & $1.890 / 1.820$ & $30.20 / 30.23$ & $7.3 \times 10^{-3}$ & 0.83 & 249 & -300 & \\
\hline $\begin{array}{c}\text { TTAN2 } \\
\text { (annealed) }\end{array}$ & $\begin{array}{l}\mathrm{Ti} / \mathrm{Ti}_{.}{ }_{62} \mathrm{Al}_{38} \mathrm{~N}_{1} / \\
\mathrm{TiAlO}_{\mathrm{x}} / \mathrm{Al}_{2} \mathrm{O}_{3}\end{array}$ & $\begin{array}{l}0.7 / 1.8 / \\
0.06 / 0.04\end{array}$ & \begin{tabular}{|l|}
$46.79 / 54.03$ \\
\end{tabular} & $10.58 / 3.611$ & $10.51 / 4.176$ & $3.3 \times 10^{-2}$ & 11.1 & -335 & -305 & \\
\hline $\mathrm{CN} 1$ & $\mathrm{Cr}_{1} \mathrm{~N}_{1}$ & 2 & $67.80 / 66.95$ & $0.459 / 0.272$ & $2.883 / 1.800$ & $1.9 \times 10^{-2}$ & 0.7 & -15 & -180 & $2.0 \times 10^{-12}$ \\
\hline $\mathrm{CCN} 2$ & $\mathrm{Cr} / \mathrm{Cr}_{1} \mathrm{~N}_{1}$ & $0.7 / 2$ & $67.12 / 67.81$ & $0.147 / 0.179$ & $1.746 / 2.069$ & $1.0 \times 10^{-2}$ & 1.5 & -40 & -290 & \\
\hline $\begin{array}{c}\mathrm{CCN} 2 \\
\text { (annealed) }\end{array}$ & $\begin{array}{l}\mathrm{Cr} / \mathrm{Cr}_{1} \mathrm{~N}_{1} / \\
\mathrm{Cr}_{2} \mathrm{O}_{3}\end{array}$ & \begin{tabular}{|l}
$0.7 / 2 /$ \\
0.05
\end{tabular} & $44.75 / 48.43$ & $-2.279 / 2.244$ & $-0.186 / 0.700$ & $5.1 \times 10^{-3}$ & 0.3 & -175 & -280 & \\
\hline
\end{tabular}

$\$$ before and after corrosion test in $\mathrm{HCl}(3.4 \%)$

Table 1: Comparison of the experimental results of all samples. The data $L^{*}$ (brightness) and $a^{*}$ and $b^{*}$ (chromaticity) were obtained from reflectance spectra. The corrosion currents $i_{\text {corr }}$ refer to the corrosion obtained during a sweep from $-500 \mathrm{mV}$ to $+500 \mathrm{mV}$ obtained in a solution of $\mathrm{NaCl} \mathrm{9 \%}$ and $\mathrm{HCl} 3.4 \%$, respectively. The Open Circuit Potential (OCP) refers to the potential relatively to a SCE-electrode obtained $1 \mathrm{~h}$ after initiating the test.

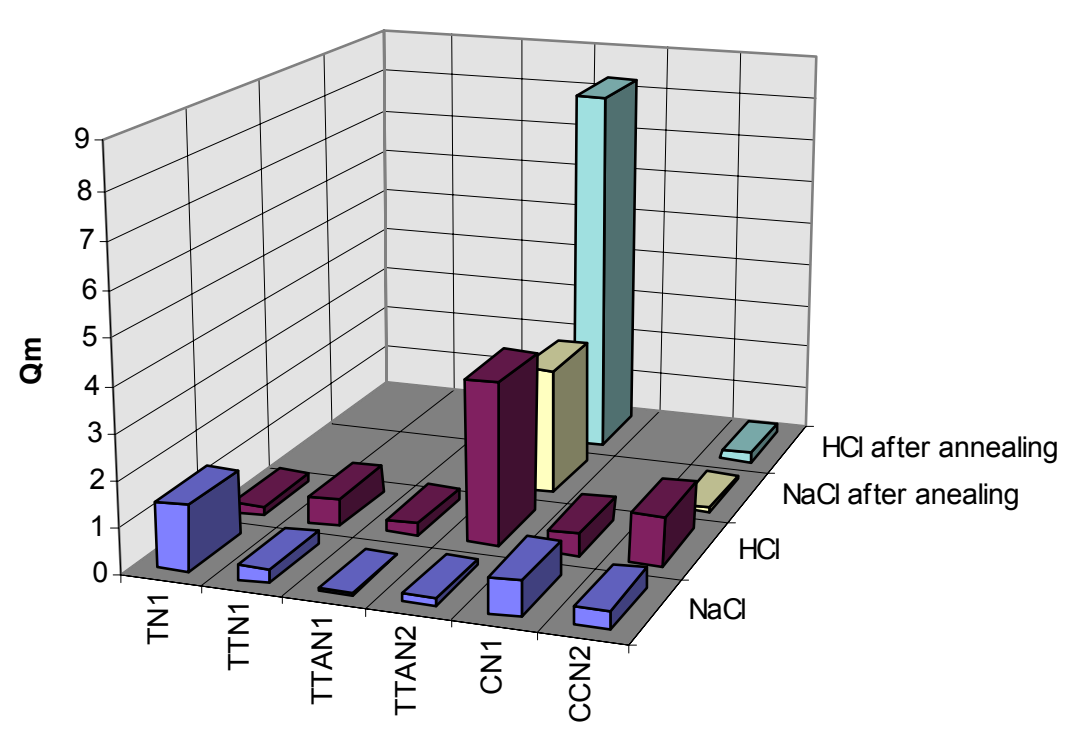


Fig. 1: Relative corrosion rates Qm in saline ( $\mathrm{NaCl}$ ) and acidic (HCl) environment of samples with hard coatings. The corrosion rates are normalised to the respective corrosion rates of stainless steel protected by a $0.7 \mu \mathrm{m}$ thick Ti metal layer. Ratios greater than unity indicate a reduction of the corrosion protection.

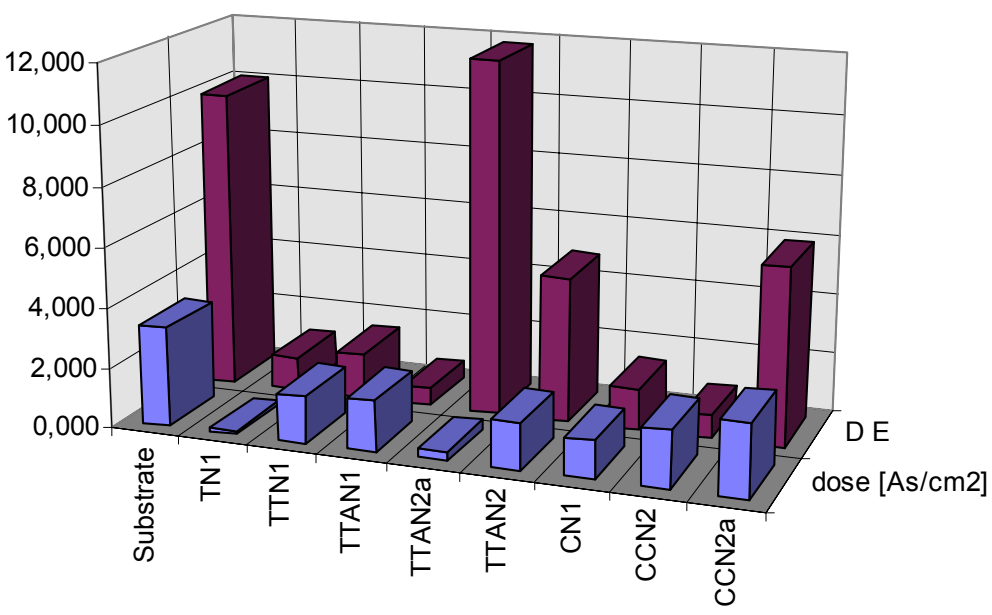

Fig.2: Absolute colour variation of the samples during the corrosion test in $\mathrm{HCl}(3.4 \%)$. The colour variation of the bare substrate is indicate, although the corrosion mechanism may be very different. The integrated corrosion current [A s/cm $\left.{ }^{2}\right]$ during the test is given also. The index a indicates the corrosion experiments with the annealed samples. 